\title{
Revised crystal structure of dehydrated Na-Type A zeolite
}

\author{
By J. V. Smirh
}

Department of the Geophysical Sciences, University of Chicago

\author{
and L. G. DoweLL
}

Union Carbide Corporation, Linde Division

(Received January 3, 1967)

\begin{abstract}
Auszug
Die früher aus Diffraktionsdaten von Pulver bestimmte Struktur wurde bestätigt. Auf Grund neuer Messungen, die an einem sehr kleinen Einkristall durchgeführt wurden, ergaben sich jedoch einige Verbesserungen. $\mathrm{Na}(1)$ ist vom Zentrum eines Sechserrings von Sauerstoffatomen aus um 0,4 $\AA$ in den großen Zwischenraum hinein versetzt. Daraus resultiert eine Dreierkoordination mit drei Sauerstoffatomen im Abstand von 2,3 $\AA$ und drei anderen im Abstand. von $3,0 \AA . \mathrm{Na}(2)$ ist vom Zentrum eines Achterrings von Sauerstoffatomen praktisch innerhalb der Ringebene versetzt. Die Koordination ist mit Sauerstoffatomen im Abstand von 2,5, 2,9, 3,5, 4,1 und 4,3 $\AA$ recht ungewöhnlich.
\end{abstract}

\section{Abstract}

The structure determined earlier from $x$-ray powder diffraction data has been confirmed but changed in detail by new data obtained for a tiny single crystal. $\mathrm{Na}(1)$ is displaced $0.4 \AA$ into the large cavity from the center of a ring of six oxygen atoms, resulting in effective three-fold coordination with three oxygen atoms at $2.3 \AA$ and three others at $3.0 \AA . \mathrm{Na}(2)$ is displaced $1 \AA$, nearly in the plane of the ring, from the center of a ring of eight oxygen atoms. The coordination is even more unusual with oxygen atoms at 2.5, 3.0,3.4, 4.0 and $4.1 \AA$.

\section{Introduction}

The synthetic products of zeolite Type A described by BREck et al. (1956) were too small for single crystal work, and the crystal structures of various ionic forms were derived from powder diffraction data ${ }^{1}$ by REED and BRECK (1956) using simple trial-and-error calculations. Later Broussard and SHowmaker (1960) refined the structure of

1 Visual estimates of spots on single-crystal photographs were used to resolve some of the ambiguities of the powder data. 
hydrated-Na-Type A zeolite using a least-squares adjustment of powder data. Howelu (1960) refined the cation positions of dehydrated Na-Type A zeolite by trial-and-error fit with powder data utilizing calculations of the electrostatic field as a guide. As a result of these investigations the alumino-silicate framework can be regarded as being established beyond doubt except for the nature of ordering of the $\mathrm{Al}$ and $\mathrm{Si}$ atoms. Although detailed measurements have not been made, the observation of superstructure reflections by BARRer and Meier (1956) and the application of the aluminumsilicon alternation rule imply with negligible doubt regular alternation of $\mathrm{Si}$ and $\mathrm{Al}$ over the tetrahedral sites. The principal uncertainty for the anhydrous $\mathrm{Na}$-Type A zeolite concerns the positions of the $\mathrm{Na}$ cations. REED and BRECK placed $8 \mathrm{Na}(1)$ at $(.188, .188, .188)$ near the center of a six-ring of oxygen atoms while How ELL placed them statistically on the 24 -fold position $(.242, .242, .171)$ : i.e. the single position on the triad axis was replaced by a trio of positions displaced about $1 \AA$ from each other. REED and BRECK placed three of the remaining four $\mathrm{Na}$ in site $\mathrm{Na}(2)$ near the centers of the rings of eight oxygen atoms at $(.410, .410,0)$ while Howell moved the position to $(.5, .41, .04)$. The assignment of the atoms, eight to the six-rings and three to the eight-rings explained the sorption data nicely, but the uncertainty of coordination made further investigation desirable. Crystals just large enough to warrant collection of x-ray data by single crystal techniques were located: although the data are not as extensive as is normally desirable, the results extend the previous conclusions. The results are also of interest in showing the limitations of $\mathrm{x}$-ray diffraction analysis applied to small crystals.

\section{Experimental (L. G. DowelL)}

The product of a suitable synthesis was examined microscopically. Although most of the larger units were agglomerates or consisted of interpenetrating twins, a few were single crystals. A perfect cube, 23 microns on edge, was placed in a glass capillary drawn down to about 50 microns inside diameter. The crystal was activated at $400^{\circ} \mathrm{C}$ for 16 hours in a near-vacuum, and the capillary sealed off. Weissenberg x-ray data confirmed the cell edge of $12.28 \AA$ found earlier by powder techniques. Integrated $\mathrm{x}$-ray data were obtained by an omega-scan about [001] using a Weissenberg goniometer. Copper $K \alpha$ radiation from a high-yield Norelco tube operated at $50 \mathrm{kV}$ and $20 \mathrm{~mA}$ was detected by a scintillation counter followed by 
pulse-height discrimination. Gas scattering was reduced by flowing helium through the goniometer. The omega scan was made over a $2^{\circ}$ range at $1^{\circ}$ per 100 seconds preceded and followed by a background measurement of 100 seconds at each end of the scan. A few reflections were scanned more than once. Non-equivalent reflections were measured for layers with $l=0,1,2$ and 3 for $\sin \theta$ up to 0.77. Because of statistical fluctuations 41 out of 192 reflections had negative integrated intensities. Of the remaining 150 reflections, 72 yielded intensities three times greater than the probable error calculated from $.675\left(N_{n}+N_{b}\right)^{\frac{1}{2}}$ where $N_{n}$ and $N_{b}$ are the total and background counts. No absorption correction was made.

Least-squares refinements and difference Fourier syntheses were calculated. The atomic form factors were adjusted empirically for half-ionization. Because of the paucity of the data, several weighting schemes were used in order to determine their effect on the atomic parameters. The results of two schemes (one using unit weights and one using weights derived from the counting statistics) are shown in Table 1. It may be seen that shifts of parameters are much greater than the random errors determined by the least-squares procedures.

Table 1. Atomic coordinates

\begin{tabular}{|c|c|c|c|c|c|c|c|c|c|}
\hline \multirow{2}{*}{ Atom } & \multirow{2}{*}{$\begin{array}{l}\text { Multi- } \\
\text { plicity }\end{array}$} & \multicolumn{4}{|c|}{ Unit weights } & \multicolumn{4}{|c|}{ Chosen weights } \\
\hline & & $x$ & $y$ & $z$ & $B$ & $x$ & $y$ & $z$ & $B$ \\
\hline $\mathrm{T}$ & 24 & $\begin{array}{r}.3686 \\
9\end{array}$ & $\begin{array}{r}1850 \\
9\end{array}$ & 0 & $\begin{array}{r}1.6 \\
3\end{array}$ & $\begin{array}{r}.3701 \\
9\end{array}$ & $\begin{array}{r}1820 \\
11\end{array}$ & 0 & $\begin{array}{r}0.0 \\
3\end{array}$ \\
\hline $\mathrm{O}(1)$ & 24 & $\begin{array}{r}1115 \\
17\end{array}$ & .1115 & $\begin{array}{r}.3387 \\
27\end{array}$ & $\begin{array}{r}3.8 \\
8\end{array}$ & $\begin{array}{r}.1117 \\
12\end{array}$ & .1117 & $\begin{array}{r}.3399 \\
15\end{array}$ & $\begin{array}{r}1.5 \\
6\end{array}$ \\
\hline $\mathrm{O}(2)$ & 12 & 0 & $\begin{array}{r}.2120 \\
28\end{array}$ & .5 & $\begin{array}{r}0.9 \\
8\end{array}$ & 0 & $\begin{array}{r}.2343 \\
27\end{array}$ & .5 & $\begin{array}{l}2.0 \\
1.1\end{array}$ \\
\hline $\mathrm{O}(3)$ & 12 & $\begin{array}{r}.3006 \\
24\end{array}$ & .3006 & 3 & $\begin{array}{l}3.2 \\
1.0\end{array}$ & $\begin{array}{r}.3016 \\
17\end{array}$ & .3016 & 0 & $\begin{array}{l}1.1 \\
1.1\end{array}$ \\
\hline $\mathrm{Na}(1)$ & 8 & $\begin{array}{r}.2133 \\
22\end{array}$ & .2133 & .2133 & $\begin{array}{l}7.6 \\
1.2\end{array}$ & $\begin{array}{r}.2124 \\
14\end{array}$ & .2124 & .2124 & $\begin{array}{l}1.4 \\
0.8\end{array}$ \\
\hline $\mathrm{Na}(2)$ & 4 & .5 & $\begin{array}{r}4074 \\
72\end{array}$ & $\begin{array}{r}.0225 \\
99\end{array}$ & $\begin{array}{l}3.5 \\
2.3\end{array}$ & .5 & $\begin{array}{r}.4376 \\
54\end{array}$ & $\begin{array}{r}.0425 \\
69\end{array}$ & $\begin{array}{l}1.3 \\
3.3\end{array}$ \\
\hline
\end{tabular}

See Table 2 for chosen weights.

The lower of each pair of numbers is the random error obtained from the least-squares refinement. 
The use of the Cruickshank weighting scheme led to even greater disparities: indeed, this weighting scheme indicated the occurrence of a peak at the center of a ring of four oxygen atoms, an unlikely position from the crystal chemical viewpoint. Detailed examination of the data showed that the principal effect of the weighting schemes consisted of shifting the burden of refinement from the stronger to the weaker intensities. Of the possible causes of errors, counting statistics, misaligment, extinction, absorption etc., it was thought that the counting statistical error was the most important. The refinement with equal weights reduced the emphasis on the weaker reflections and decreased the emphasis on extinction and other errors which affect mainly the strong intensities. Although it is thought that the most reasonable result lies between those obtained for the refinements with unit weights and with weights obtained from the counting statistics, it seemed unrealistic to attempt further adjustment of the weighting scheme. Instead it was decided to rely only upon those features of the crystal structure which consistently appeared in the least-squares refinements and in the difference Fourier syntheses whatever the weighting scheme. Table 2 lists the observed and calculated structure amplitudes together with chosen weights based

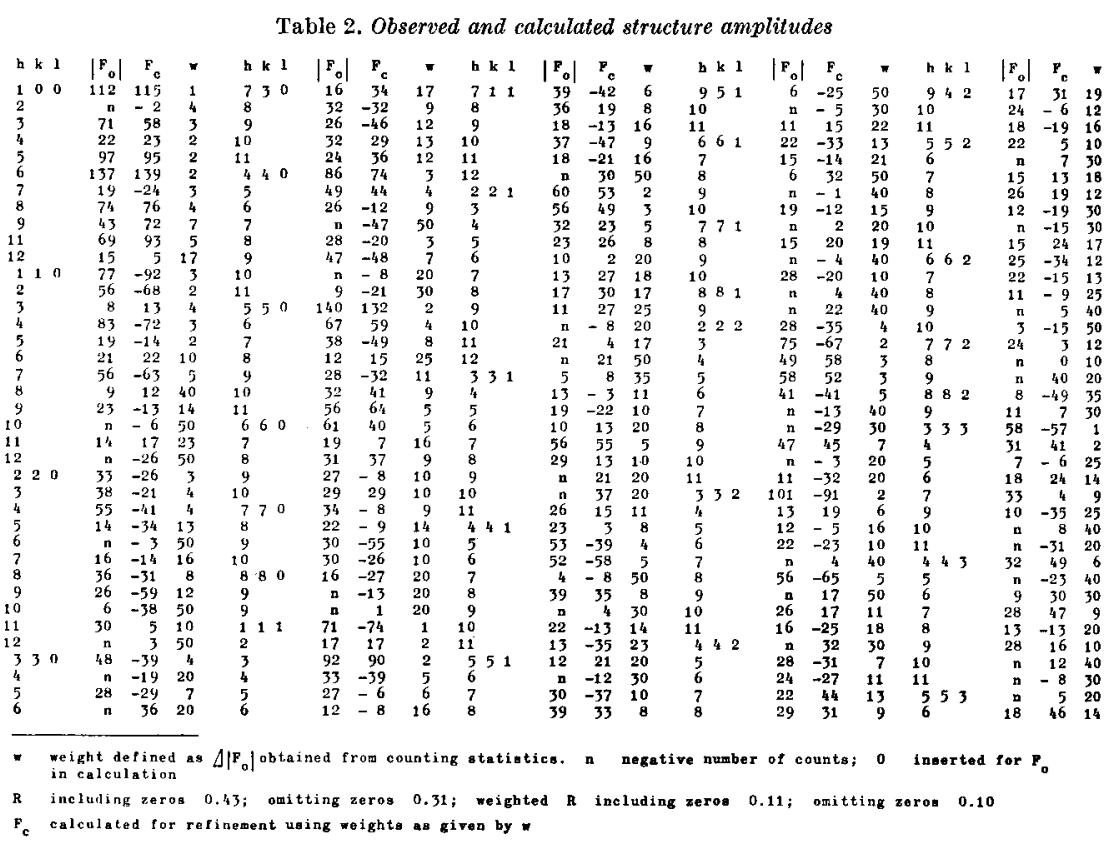


Table 3. Interatomic distances

\begin{tabular}{l|c|c|c|c|c}
\hline & $\begin{array}{c}\text { Unit } \\
\text { weights }\end{array}$ & $\begin{array}{c}\text { Chosen } \\
\text { weights }\end{array}$ & & $\begin{array}{c}\text { Unit } \\
\text { weights }\end{array}$ & $\begin{array}{c}\text { Chosen } \\
\text { weights }\end{array}$ \\
\hline $\mathrm{T}-\mathrm{O}(1)$ & 1.68 & 1.66 & $\mathrm{Na}(1)-\mathrm{O}(1)$ & 2.34 & 2.35 \\
$\mathrm{~T}-\mathrm{O}(2)$ & 1.65 & 1.72 & $\mathrm{Na}(1)-\mathrm{O}(3)$ & 3.03 & 3.03 \\
$\mathrm{~T}-\mathrm{O}(3)$ & 1.65 & 1.70 & $\mathrm{Na}(2)-\mathrm{O}(2)$ & 2.4 & 2.5 \\
mean & 1.66 & 1.69 & $\mathrm{Na}(2)-\mathrm{O}(3)$ & 2.8 & 3.0 \\
$\mathrm{O}(1)-\mathrm{O}(1)^{\prime}$ & 2.74 & 2.74 & $\mathrm{Na}(2)-\mathrm{O}(2)^{\prime}$ & 3.7 & 3.4 \\
$\mathrm{O}(1)-\mathrm{O}(2)$ & 2.71 & 2.83 & $\mathrm{Na}(2)-\mathrm{O}(3)^{\prime}$ & 4.3 & 4.0 \\
$\mathrm{O}(1)-\mathrm{O}(3)$ & 2.74 & 2.75 & $\mathrm{Na}(2)-\mathrm{O}(2)^{\prime \prime}$ & 4.6 & 4.1 \\
$\mathrm{O}(2)-\mathrm{O}(3)$ & 2.68 & 2.57 & & &
\end{tabular}

on the counting statistics (one reflection, 833, was omitted because of a gross discrepancy between observed and calculated amplitudes thought to be the result of a mis-setting). Table 3 shows the interatomic distances calculated for the coordinates of Table 1 .

\section{Discussion}

The features of the structure which are immune to the weighting schemes are as follows: the nature of the alumino-silicate framework, full or nearly-full occupancy by sodium atoms of the eight sites near to centers of the rings of six oxygen atoms without displacement from the triad axis, and statistical occupancy by sodium atoms of positions near to the centers of the rings of eight oxygen atoms (Fig. 1).

It is not possible from the present data to determine accurately the occupancy factor for the sodium atoms because of the strong interaction with the artificial temperature factor during refinement, and because of the strong effect of the weighting scheme. However the reasonableness of the temperature factors for the $\mathrm{T}$ and $\mathrm{O}$ atoms in the refinement using the chosen weights when compared with those commonly found in framework alumino-silicates (viz. 0.6 for $\mathrm{T}$ and $\mathbf{1 . 5}$ for $\mathrm{O}$ ) suggests that the results of this refinement for the $\mathrm{Na}$ atoms are indicative. In this refinement $8 \mathrm{Na}$ were assigned to the $\mathrm{Na}(1)$ position and four to $\mathrm{Na}(2)$; the resulting temperature factors of $1.4 \pm 0.8$ and $1.3 \pm 3.3$ lie in the range of values found for large cations in framework alumino-silicates, suggesting that these occupancy factors are reasonable. However the actual number of sodium atoms near the eight rings is uncertain. There are three sets of four positions, each set probably occupied by only one sodium atom on a statistical basis. If this is true, one sodium atom is unlo- 
cated, and is probably to be found on the inner surface of the large cavity. The possibility that two positions out of one set are occupied simultaneously is quite unlikely from a chemical viewpoint. The present calculations cannot distinguish between the possible distributions.

The $\mathrm{Na}(1)$ atoms are assigned to a single site on the triad axis at $x x x$ with $x$ near .212. A least-square refinement of the trio of positions used by Howelu led to the single site on the triad axis: in addition, no evidence for lack of circular symmetry was found in

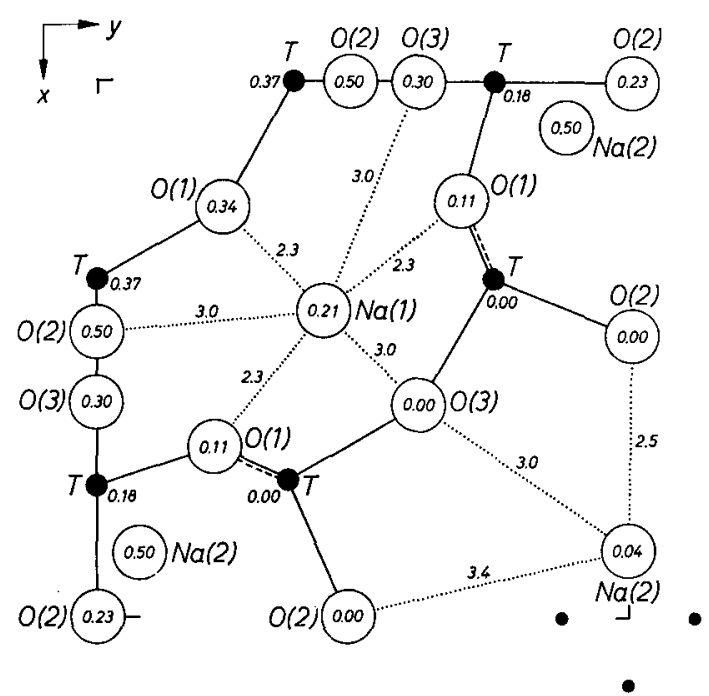

Fig. 1. Atomic positions and cation-oxygen distances for the parameters obtained by least-squares refinement using chosen weights. Only one of the positions for $\mathrm{Na}(2)$ is marked prominently: the other three possible positions are marked by dots. The heights along the $z$ axis are shown by two figure decimals

an $F_{0}$ synthesis. Whereas the position of the $\mathrm{Na}(1)$ atom is almost immune to the weighting scheme, that of the $\mathrm{Na}(2)$ atom is strongly affected. Within the large uncertainty the position of $\mathrm{Na}(2)$ is consistent with that derived by HoweLL.

The positional coordinates of the framework are hardly affected by the choice of weighting scheme except for the $y$ coordinate of $O(2)$ which is extremely sensitive. The T-O distances for either refinement are consistent with the expected value of $1.68 \AA$ for a framework structure with unit ratio of $\mathrm{Si}$ to $\mathrm{Al}$. In contrast to the unusually small values of the $\mathrm{Na}-\mathrm{O}$ distances found by HowELL, 
none of the values found here is smaller than the normal range of $2.3 \AA$ upwards found in other structures. However the coordinations are most unusual. $\mathrm{Na}(1)$ is close to six oxygens, three at $2.3 \AA$ and three at 3.0 $\AA$. The marked difference in these distances would indicate that coordination is primarily to the three $O(1)$ atoms at $2.3 \AA$ which lie at the base of a trigonal pyramid with $\mathrm{Na}(1)$ at the apex; the height of the pyramid is $0.5 \AA$ with the apex projecting away from the plane of the $O(1)$ atoms into the larger cavity. The coordination of the $\mathrm{Na}(2)$ atom is even more unusual. Although the positional coordinates are quite uncertain, both the least-squares refinements and the Fourier syntheses definitely indicate statistical occupancy of sites displaced about $1 \AA$ from the centers of the rings of eight oxygen atoms, the displacement being close to the plane of the ring. The closest approaches to the oxygen atoms are 2.5, 3.0 (twice) and 3.4 (twice) $\AA$; the next-nearest approaches are over $4 \AA$. If coordination is assumed to occur only to the five closer oxygen atoms, the coordination polyhedron consists of a very flat pentagonal pyramid. Although this is most unusual, there is no position near the eight-ring which can provide a normal coordination polyhedron. Of course, in the hydrated zeolite the water molecules may provide the missing parts of the coordination polyhedron though the sites for the Na atoms are not necessarily the same in the hydrated and anhydrous varieties. In spite of the unusual coordinations, the charge balance of the structure may be fairly good: although $\mathrm{Na}(1)$ is principally bonded to $\mathrm{O}(1)$, and $\mathrm{Na}(2)$ to $\mathrm{O}(2), \mathrm{O}(3)$ may be weakly bonded to both $\mathrm{Na}(1)$ and $\mathrm{Na}(2)$ thus providing a reasonable sharing-out of the cationic charge. It should be emphasized that the structure derived here is an average structure based on the $12 \AA$ pseudo-cell with symmetry $P m 3 m$ : the true structure must be more complex.

Probably better results on small crystals for a given measurement period would be obtained by the stationary crystal method in place of the scanning technique, though there would be added danger of errors resulting from misalignment.

\section{Acknowledgements}

We thank Miss E. Flanigen for her continual good advice with zeolite problems, Mr. C. R. KNowles for assistance with the calculations and both the Petroleum Research Fund administered by the American Chemical Society and Union Carbide Corporation for grants-in-aid. 


\section{References}

R. M. BARRER and W. M. MEIER (1956), Structural and ion sieve properties of a synthetic crystalline exchanger. Trans. Faraday Soc. 54, 1074-1085.

D. W. Breck, W. G. Eversole, R. M. Milton, T. B. Reed and T. L. Thomas (1956), Crystalline zeolites I. The properties of a new synthetic zeolite, Type A. J. Amer. Chem. Soc. 78, 5963-5971.

L. Broussard and D. P. Shommaker (1960), The structures of synthetic molecular sieves. J. Amer. Chem. Soc. 82, 1041-1051.

P. A. Howexl (1960), A refinement of the cation positions in synthetic zeolite Type A. Acta Crystallogr. 13, 737-741.

T. B. ReED and D. W. Breck (1956), Crystalline zeolites. II. Crystal structure of synthetic zeolite, Type A. J. Amer. Chem. Soc. 78, 5972-5977. 